\title{
Discussion
}

on paper published in

Magazine of Concrete Research

1993, 45, No. 164, Sept., 179-186

\section{Effects of urea on durability of reinforced concrete}

\author{
M. Sadegzadeh, C. L. Page and P. R. W. Vassie \\ Contribution by B. Mather \\ Director, Structures Laboratory, US Army Engineer Waterways Experiment Station, \\ Vicksburg, MS 39180-6199, USA
}

I found it both interesting and gratifying that the Authors conclude from their thorough investigation that 'urea does not adversely affect the durability of reinforced concrete', since that is the conclusion I previously reached, on much less evidence. However, they add the caveat 'except where there is an accumulation of urea crystal growth', which, as they point out, is irrelevant to the practical considerations with which they are concerned. This caveat is based on the finding that 'During the drying cycle, urea crystal growths left on the surface of the specimens were large, needle-like and parallel to the surface, and their presence did not cause damage .... However, when they grew on the sides of the 'pond' the crystals had a different morphology; they were fine and equiaxed, and they resulted in spalling away of several $\mathrm{mm}$ of concrete cover in places'. When there is an association of concrete deterioration by scaling, spalling, or similar behaviour and some process that involves precipitation of a solid from solution there has been a tendency in the literature to assume that the solid, especially if it is crystalline (like ice), exerts some force of 'crystal growth' that pushes on the surroundings of the space in which the precipitation takes place. I do not believe this is true. When sodium sulphate or magnesium sulphate solutions are used to simulate the action of freezing and thawing on porous rigid solid bodies such as rock or concrete as was proposed by Brard, ${ }^{1}$ discussed beautifully by Schaffer ${ }^{2}$ and employed by ASTM $\mathrm{C} 88,{ }^{3}$ it is often assumed that the damage is caused by crystal growth pressure or the force of crystal growth. This is not the case. When water is converted by a temperature-induced phase change to ice the force exerted, if any, on the surrounding is due to the $9 \%$ increase in volume accompanying the phase change. When a rock containing pores filled with sodium or magnesium sulphate solution is put in an oven and dried (as in Ref. 3 ), crystals of hydrated salt grow, they are dehydrated to an anhydrous or lower hydrate phase, then, when the rock is put back in the solution, the partially or completely dehydrated crystals expand (as does water on freezing), and if the pore has enough such material in it a force is exerted on the walls of the pore. This is why Brard called it a method of simulating the action of frost. I was not aware until a few years ago that this phenomenon also takes place in nature. ${ }^{4}$ The question I ask in this connection is as follows: do the Authors have an explanation of the mechanism by which the observed 'spalling away of several mm of concrete cover' took place? In the case of the deicer scaling test of ASTM C672, ${ }^{5}$ I have assumed that what was being measured was the frost resistance of the near-surface portion of the concrete - which often has inferior frost resistance to the material lower down in the structure.

A second issue that came to mind as I read the Paper involves unpublished results of a detailed study done here in 1974-1975 of causes of pavement scaling at an airfield in Germany. In the course of exploring possible mechanisms of such scaling, we examined the interaction of urea solutions (since the US Air Force uses urea to 
deice its aircraft) with the slightly altered, rather coarsetextured basic igneous rock that was used as coarse aggregate. What we found was that some particles of the rock had the feldspar phenocrysts altered to smectite on the grain boundaries, which allowed urea to enter and form a clay-organic complex that disaggregated the particle into its constituent feldspar grains. A fascinating phenomenon, but unrelated to our study, since the pavement in question had been built with over-sanded, well-vibrated concrete in which no coarse aggregate particle was less than $10 \mathrm{~mm}$ from the surface and all the scaling was less than $5 \mathrm{~mm}$ deep. However, one might bear in mind that urea can form a complex with smectite that could contribute to concrete deterioration. After all, as recorded by $\mathrm{K}$. Mather, ${ }^{6}$ one of the earliest investigations of a failure of concrete ascribed to constituents of the aggregate ${ }^{7}$ involved altered feldspar in igneous rock (amorthosite) used as aggregate.

\section{Reply by the Authors}

We thank Mr Mather for his interesting and informative comments on our Paper and are pleased to acknowledge that our evidence provides general support for his views regarding the durability of concrete exposed to urea as a deicing agent. We do not, however, understand his reasons for dismissing restrained crystal growth within a porous material as a potential mechanism of damage to the pore walls. The phenomenon has been widely reported in the literature and, according to the Building Research Establishment, crystallization damage is the most important cause of stone decay in the UK, where it has been associated with a variety of salts. ${ }^{8}$ The mechanism is believed to be somewhat similar to that proposed by Everett ${ }^{9}$ in relation to frost action, and an outline is presented below.

In a system of widely varied pore sizes containing a supersaturated solution and subjected to drying, it is likely that nucleation and growth of a precipitate will be confined to the larger sub-surface pores, because it is from them that solvent evaporation occurs preferentially and within them that the necessary steric rearrangements to form a critical nucleus can be accommodated most readily. Given that the finer pores, in which precipitation is suppressed, remain filled with supersaturated solution, there will be a thermodynamic tendency for solute to migrate from them into the larger pores. This process would be expected to continue, feeding the growth of precipitate within the larger pores so that the latter eventually become filled to an extent that may cause deformation of the surrounding pore walls.

We believe that the surface damage caused by urea to the cement matrix at the sides of the ponded and dried concrete specimens we examined was of the above nature, although we did not characterize the mechanism of the process in detail. The aggregates in the concrete were composed of Bunter quartzite from the upper Trent valley, and it seems unlikely that they were involved in any significant way.

\section{References}

1. De Thury H. On the method proposed by Mr. Brand for the immediate detection of stones unable to resist the action of frost. Ann. Chem. Phys., 1828, 38, 160-192.

2. SCHAFFER R. J. The weathering of natural building stores. Building Research Special Report 18, HMSO, London.

3. ASTM. Standard test method for soundness of aggregates by use of sodium sulfate or magnesium sulfate. Designation C88-90, Annual book of standards, Vol. 04.02, 1993, American Society for Testing and Materials, Philadelphia, PA.

4. Binda L. and Baronio G. Mechanisms of masonry decay due to salt crystallization. Durability of building materials, Vol. 4, 1987 , pp. $227-240$.

5. ASTM. Standard test method for scaling resistance of concrete surfaces exposed to deicing chemicals. Designation C672-92, Annual book of standards, Vol. 04.02, 1993, American Society for Testing and Materials, Philadelphia, PA.

6. MATHER K. Applications of light microscopy in concrete research. In Symposium on light microscopy, STP143, 1952, pp. 51-70. American Society for Testing and Materials, Philadelphia, PA.

7. Pearson J. C. and Loughlin G. F. An interesting case of dangerous aggregate, Proc. Am. Concr. Inst., 1923, 19, 142.

8. Price C. A. Stone - decay and preservation. Chem. Br., 1975, 11, No. 10, 350-353.

9. EveretT D. H. Frost damage to roads and buildings. New Scientist, 1962, 269, 68-70. 